\title{
Uso de probióticos na produção de pós-larvas de camarão-rosa
}

\author{
Emanuell Felipe Beserra da Silva( ${ }^{(1)}$, Charles Nunes Fróes ${ }^{(2)}$, Diego Moreira de Souza ${ }^{(2)}$, \\ Roberta Soares $^{(3)}$, Silvio Peixoto( ${ }^{(3)}$, Wilson Wasielesky ${ }^{(2)}$ e Eduardo Luis Cupertino Ballester ${ }^{(4)}$
}

\begin{abstract}
(1)Universidade Federal da Paraíba, Centro de Ciências Humanas, Sociais e Agrárias, Departamento de Gestão e Tecnologia Agroindustrial, Cidade Universitária, CEP 58220-000 Bananeiras, PB. E-mail: emanuellfelipe@yahoo.com.br (2)Universidade Federal do Rio Grande, Instituto de Oceanografia, Laboratório de Carcinicultura, CEP 96201-900 Rio Grande, RS. E-mail: charlesfroes@gmail.com, the_best@hotmail.com, manow@mikrus.com.br ${ }^{(3)}$ Universidade Federal Rural de Pernambuco, Departamento de Pesca e Aquicultura, Laboratório de Tecnologia em Aquicultura, CEP 52171-900 Recife, PE. E-mail: beta.ufrpe@gmail.com, silvio.peixoto@gmail.com (4)Universidade Federal do Paraná, Campus Palotina, Laboratório de Carcinicultura, CEP 85950-000 Palotina, PR. E-mail: elcballester@yahoo.com.br
\end{abstract}

Resumo - O objetivo deste trabalho foi avaliar o uso de probióticos na produção de pós-larvas do camarão-rosa (Farfantepenaeus brasiliensis). Utilizou-se o delineamento experimental inteiramente casualizado, com dois tratamentos - uso de probióticos (Bacillus spp.) e controle com uso de antibiótico (eritromicina) - e quatro repetições. Pós-larvas no estágio $\mathrm{PL}_{1}$ foram estocadas em cada parcela experimental $(3,0 \mathrm{~L})$ e cultivadas até o estágio $\mathrm{PL}_{10}$. As variáveis de qualidade de água e o desenvolvimento de bactérias do gênero Vibrio, na água de cultivo, foram monitorados ao longo do experimento. Ao final do período experimental, as pós-larvas foram avaliadas qualitativamente e quanto à sobrevivência, ao peso e ao comprimento. Nas variáveis de qualidade de água, apenas o nitrito apresentou valor significativamente maior no tratamento com antibiótico. Para as variáveis peso e comprimento final, não houve diferenças significativas entre os tratamentos. Não foram observadas diferenças significativas entre os tratamentos quanto à qualidade das pós-larvas e à concentração de Vibrio spp. na água. A utilização de antibiótico pode ser substituída pelo emprego de probióticos durante a produção de pós-larvas de F. brasiliensis.

Termos para indexação: Bacillus, Farfantepenaeus brasiliensis, Vibrio, antibiótico, crescimento, sobrevivência.

\section{Use of probiotics in the production of pink shrimp postlarvae}

\begin{abstract}
The objective of this work was to evaluate the use of probiotics in the production of postlarvae of pink shrimp (Farfantepenaeus brasiliensis). A completely randomized experimental design was used, with two treatments - use of probiotics (Bacillus spp.), and a control using antibiotic (erythromycin) -, and four replicates. Postlarvae in the $\mathrm{PL}_{1}$ stage were stocked in each experimental unit $(3.0 \mathrm{~L})$ and cultured until stage $\mathrm{PL}_{10}$. Water quality variables and the development of the bacteria of the genus Vibrio, in the culture water, were monitored throughout the experiment. At the end of the experimental period, postlarvae were evaluated qualitatively and for survival, weight, and length. Regarding water quality variables, only nitrite was significantly higher in the antibiotic treatment. For the variables weight and length, there were no significant differences between treatments. No significant differences between treatments were observed in postlarvae quality and in the concentration of Vibrio spp. in the water. The use of antibiotics may be replaced by probiotics during production of $F$. brasiliensis postlarvae.
\end{abstract}

Index terms: Bacillus, Farfantepenaeus brasiliensis, Vibrio, antibiotic, growth, survival.

\section{Introdução}

A produção de camarão marinho no Brasil é realizada quase na sua totalidade com a espécie exótica Litopenaeus vannamei. Entretanto, espécies nativas, como o camarão-rosa, Farfantepenaeus brasiliensis, já mostraram potencial para o cultivo (Lopes et al., 2009). Para esta espécie, ainda há pouco conhecimento quanto a aspectos biológicos e fisiológicos (Brito et al., 2000), ao cultivo (Lopes et al., 2009) e à distribuição, que vai desde a Carolina do Norte, EUA, até a costa do Rio Grande do Sul (Gaxiola et al., 2010).
A produção de pós-larvas de qualidade é fundamental para o cultivo e o repovoamento de espécies nativas de camarões. Durante a produção de pós-larvas de peneídeos, bactérias do gênero Vibrio são uma das principais causas de mortalidade. Essas bactérias são consideradas oportunistas e podem causar doenças em condições subótimas de cultivo. Elas estão presentes na água de cultivo, na flora intestinal de larvas e no alimento vivo consumido pelos camarões (Decamp et al., 2008).

Tradicionalmente, antibióticos e produtos químicos têm sido utilizados para o controle de doenças bacterianas na aquicultura; porém, o uso massivo 
dessas substâncias tem proporcionado resistência nos microrganismos (Defoirdt et al., 2007). Karunasagar et al. (1994) relataram mortalidade em massa de larvas do camarão tigre, Penaeus monodon, causada por Vibrio harveyi, com múltipla resistência a antibióticos, como cotrimoxazol, cloranfenicol, eritromicina e estreptomicina. Neste contexto, o uso de bactérias benéficas (probióticos) tem sido recomendado em substituição ao uso de antibióticos na aquicultura (Ravi et al., 2007). Diversos estudos têm reportado o uso desses orgnismos na aquicultura (Gram et al., 1999; Panigrahi et al., 2004; Decamp et al., 2008).

O termo probiótico, em aquicultura, aplica-se ao uso de suplementos microbianos vivos que tenham efeitos benéficos para o hospedeiro e para o ambiente de cultivo, em razão da modificação da comunidade microbiana, com melhor aproveitamento do alimento artificial, maior crescimento e sobrevivência, melhor resposta imunológica do hospedeiro a doenças e manutenção da qualidade da água (Verschuere et al., 2000; Decamp et al., 2008). Probióticos baseados em bactérias gram-positivas do gênero Bacillus são uma alternativa à terapia antibiótica contra Vibrio (Rengpipat et al., 2000; Hong et al., 2005). Essas bactérias competem por nutrientes e, portanto, inibem o rápido crescimento de Vibrio e de outras bactérias, o que permite que bactérias resistentes não se multipliquem e não transfiram genes de resistência (Hong et al., 2005). Além disso, diversos compostos antimicrobianos são naturalmente produzidos por uma gama de espécies de Bacillus (Moriarty, 1998).

Em sistemas de larvicultura, principalmente a partir do estágio $\mathrm{PL}_{1}$, há maior acúmulo de amônia e nitrito na coluna de água em razão das altas densidades de estocagem e de fezes, e ração com alto teor de proteína. O acúmulo desses compostos é um fator limitante nos sistemas de produção (Banerjee et al., 2010). Para solucionar esses problemas, é necessário realizar frequentes trocas de água dos tanques de cultivo, que resultam em descarga de resíduos que podem causar eutrofização do ambiente natural (Ziemann et al., 1992). Nos sistemas de cultivo com adição de probióticos, as trocas de água podem ser diminuídas ou até mesmo eliminadas, uma vez que os probióticos atuam na absorção e na decomposição da matéria orgânica na água e nos sedimentos, o que melhora a qualidade de água (Wang et al., 2005).
O objetivo deste trabalho foi avaliar o uso de probióticos na produção de pós-larvas do camarão-rosa F. brasiliensis.

\section{Material e Métodos}

As pós-larvas de $F$. brasiliensis utilizadas no experimento foram obtidas de fêmeas selvagens, capturadas no litoral norte do Estado de Santa Catarina e induzidas à reprodução no setor de maturação da Estação Marinha de Aquacultura, da Universidade Federal de Rio Grande, RS. O experimento foi realizado no período de fevereiro a março de 2009.

As larvas foram estocadas em um tanque de $500 \mathrm{~L}$, a $28^{\circ} \mathrm{C}$ e aeração constante, com concentrações de oxigênio acima de $6,0 \mathrm{mg} \mathrm{L}^{-1}$. Aalimentação consistiu de rações comerciais para larvicultura de L. vannamei (Inve Technologies nv, Dendermonde, Bélgica) específicas para cada fase de desenvolvimento, além da microalga Thalassiosira weissflogii na densidade de $4 \times 10^{4}$ células por $\mathrm{mL}$. A partir do estágio de $\mathrm{Zoea}_{3}$ foram ofertados náuplios de Artemia sp. congelados, ad libitum, duas vezes ao dia.

Utilizou-se o delineamento experimental inteiramente casualizado, com dois tratamentos e quatro repetições: uso de probióticos (Bacillus spp.), e controle - com uso de antibiótico (eritromicina). O tratamento probiótico consistiu no uso de probióticos comercias (Inve Technologies nv, Dendermonde, Bélgica) segundo o protocolo recomendado pelo fabricante; enquanto o tratamento controle consistiu de protocolo padrão utilizado em laboratórios comerciais para a produção de pós-larvas de camarões peneídeos, sem uso de probióticos. Como unidades experimentais, foram utilizados potes de plástico de 3,0 L, contendo 300 camarões no estágio $\mathrm{PL}_{1}$ (um dia após a metamorfose para pós-larva), com peso inicial de $0,27 \pm 0,15 \mathrm{mg}$ e comprimento de $4,54 \pm 0,05 \mathrm{~mm}$. Antes da estocagem dos animais, a água foi esterilizada com cloro por 24 horas e filtrada com filtro de cartucho de 3,0 $\mu \mathrm{m}$. As parcelas experimentais permaneceram imersas em banho térmico para manter temperatura constante de $28^{\circ} \mathrm{C}$.

Dois tipos de probióticos comerciais foram utilizados no tratamento probiótico: Sanolife MIC (Inve Technologies nv, Dendermonde, Bélgica), composto por cepas de B. subtilis, B. licheniformis e B. pumilus na concentração de $5 \times 10^{10} \mathrm{UFC} \mathrm{g}^{-1}$; e Sanolife PRO-W 
(Inve Technologies nv, Dendermonde, Bélgica), composto por cepas de B. subtilis e B. licheniformis na concentração de $5 \times 10^{10}$ UFC $\mathrm{g}^{-1}$. O probiótico foi adicionado diariamente na água de cultivo, em cada estágio de desenvolvimento, nas seguintes concentrações: $1,0 \mathrm{mg} \mathrm{L}^{-1}\left(\mathrm{PL}_{1}\right)$ e $0,5 \mathrm{mg} \mathrm{L}^{-1} \mathrm{de}$ Sanolife MIC ( $\mathrm{PL}_{2}, \mathrm{PL}_{3}$ e $\left.\mathrm{PL}_{4}\right) ; 1,0 \mathrm{mg} \mathrm{L}^{-1}$ de Sanolife MIC e 3,0 $\mathrm{mg} \mathrm{L}^{-1}$ de Sanolife PRO-W ( $\left.\mathrm{PL}_{5}\right) ; 0,5 \mathrm{mg} \mathrm{L}^{-1}$ de Sanolife MIC e 3,0 $\mathrm{mg} \mathrm{L}^{-1}$ de Sanolife PRO-W $\left(\mathrm{PL}_{6}\right)$; e 2,0 $\mathrm{mg} \mathrm{L}^{-1}$ de Sanolife PRO-W ( $\mathrm{PL}_{7}$ a $\left.\mathrm{PL}_{10}\right)$.

No tratamento probiótico, não foirealizada renovação de água. No tratamento controle, foi administrada uma dose de eritromicina na água de cultivo no primeiro dia do experimento. A partir do segundo dia, foi adicionada formalina (Delaware, Porto Alegre, RS, Brasil) diariamente na concentração de $10 \mathrm{mg} \mathrm{L}^{-1}$. Neste tratamento, foi realizada renovação diária de $50 \%$ da água do cultivo.

A alimentação consistiu de um mix de rações comerciais para pós-larvas (Inve Technologies nv, Dendermonde, Bélgica) ofertado dez vezes ao dia, a cada 2 horas, além de náuplios de Artemia na proporção de 50 náuplios por pós-larva, ofertados duas vezes ao dia (10 e $0 \mathrm{~h}$ ). No início do experimento, a microalga $T$. weissflogii foi adicionada na proporção de $0,5 \times 10^{4}$ células por $\mathrm{mL}$, e, diariamente, foram realizadas contagens residuais para reposição, caso a densidade de algas fosse inferior à densidade inicial.

A temperatura foi mantida em $28^{\circ} \mathrm{C}$ com uso de aquecedores de imersão Jebo Aqua Heater 50W, (Jebo Aquarium, Monterey Park, CA, EUA), e a salinidade permaneceu constante em 35\%. A concentração de oxigênio dissolvido $\left(\mathrm{mg} \mathrm{L}^{-1}\right)$ e $\mathrm{pH}$ foi mensurada diariamente por meio de analisador multiparâmetro YSI 556, (YSI Incorporated, World Headquarters, Yellow Springs, OH, EUA), e as concentrações $\left(\mathrm{mg} \mathrm{L}^{-1}\right)$ de nitrito $\left(\mathrm{NO}_{2}\right)$ e amônia $\left(\mathrm{NH}_{3}\right)$ foram monitoradas a cada três dias com uso dos métodos de Bendschneider \& Robinson (1952) e Chemical methods for use in marine environmental monitoring (1983), respectivamente.

$\mathrm{O}$ experimento foi finalizado quando os camarões atingiram o estágio $\mathrm{PL}_{10}$, no total de dez dias de cultivo. Foram determinados sobrevivência (\%), peso $(\mathrm{mg})$ e comprimento $(\mathrm{mm})$ de 20 animais de cada parcela experimental, com auxílio de balança com $0,0001 \mathrm{~g}$ de precisão e paquímetro, respectivamente.

O desenvolvimento de Vibrio spp. na água do cultivo foi monitorado por análise bacteriológica. Foi realizado um "pool" de cada tratamento com $250 \mu \mathrm{L}$ de cada parcela experimental, aos 0, 3, 6 e 10 dias. Foram feitas diluições seriadas com solução salina $0,85 \%$, e, em seguida, $25 \mu \mathrm{L}$ de cada diluição foi plaqueada em meio agar TCBS ("thiosulfate citrate bile salt sucrose"). As placas foram incubadas a $37^{\circ} \mathrm{C}$ por 24 horas e, posteriormente, foi realizada a leitura em UFC $\mathrm{mL}^{-1}$.

Ao final do experimento, dez pós-larvas de cada parcela experimental foram coletadas para análise qualitativa pelo método descrito por Tayamen \& Brown (1999). Foram analisados 11 critérios de qualidade para cada pós-larva: presença de cromatóforos expandidos, deformações, melanização, necroses, preenchimento de lipídeos do hepatopâncreas, número de ramificações nas brânquias, necrose nas brânquias, coloração da musculatura, grau de preenchimento do intestino, relação músculo-intestino no sexto somito abdominal e presença de epibiontes. As pós-larvas receberam notas de 0 (péssima qualidade) a 3 (ótima qualidade). Após a avaliação de cada critério, foi realizado o somatório da pontuação de cada pós-larva e, em seguida, foi calculada a pontuação média das pós-larvas avaliadas em cada tratamento.

Os dados de peso, comprimento, sobrevivência e variáveis de qualidade da água foram submetidos ao teste $\mathrm{t}$ de Student, a $5 \%$ de probabilidade. A concentração de Vibrio spp. na água de cultivo foi analisada por meio de análise de variância (duas vias) para efeitos principais (tempo $\mathrm{x}$ tratamento). Os dados da análise qualitativa das pós-larvas foram analisados por meio do teste $t$, para amostras não paramétricas. As análises estatísticas foram realizadas com auxílio do programa Statistica (StatSoft, 2004).

\section{Resultados e Discussão}

Os valores de oxigênio dissolvido, $\mathrm{pH}$, salinidade e amônia não apresentaram diferenças significativas entre os tratamentos; porém, o nitrito apresentou valor significativamente maior no tratamento com antibiótico, em comparação ao com probióticos (Tabela 1). As variáveis físicas e químicas da água no experimento foram consideradas adequadas para o cultivo de pós-larvas de camarões peneídeos (Boyd, 1990).

As maiores perdas na larvicultura de camarão são relacionadas a problemas de qualidade de água, o que pode proporcionar o desenvolvimento de bactérias 
nocivas, principalmente as do gênero Vibrio, no meio de cultivo (Decamp et al., 2008). Lakshmanan \& Soundarapandian (2008) analisaram o efeito de probióticos comerciais (Bacillus spp.) no cultivo do camarão tigre $P$. monodon e observaram que eles reduziram significativamente a concentração de nitrito e amônia na água quando comparado ao tratamento sem uso de probióticos. No presente trabalho, mesmo com as trocas de água no tratamento controle, a concentração de nitrito atingiu valores significativamente maiores em comparação ao tratamento com probióticos, o que indica maior eficiência do probiótico para manutenção da qualidade da água, sem a necessidade de renovações. Portanto, a utilização de probióticos na aquicultura permite melhoria nos parâmetros de qualidade de água, além de diminuir impactos econômicos e ambientais por meio da redução na quantidade de água utilizada e na geração de efluentes dos sistemas de produção (Ziemann et al., 1992; Wang et al., 2005).

Para as variáveis peso e comprimento final, não foram observadas diferenças significativas entre os tratamentos com probióticos e o tratamento com antibiótico (Tabela 1).

Ziaei-Nejad et al. (2006) observaram que o camarão $F$. indicus, entre os estágios Mísis ${ }_{1}$ e $\mathrm{PL}_{1-2}$, não apresentou diferenças significativas quanto ao peso quando cultivado com ou sem probiótico (Bacillus spp.); entretanto, nos estágios Mísis ${ }_{1}$ a $\mathrm{PL}_{14}$, os camarões cultivados com probiótico apresentaram maior peso, quando comparados ao tratamento sem probiótico.

Tabela 1. Médias \pm desvio-padrão de oxigênio dissolvido, $\mathrm{pH}$, nitrito e amônia da água de cultivo, e peso final, comprimento e sobrevivência de pós-larvas $\left(\mathrm{PL}_{10}\right)$ no tratamento com probióticos e controle, com antibiótico, no cultivo de pós-larvas do camarão-rosa Farfantepenaeus brasiliensis ${ }^{(1)}$.

\begin{tabular}{lcc}
\hline Variável & Probiótico & Antibiótico \\
\hline Oxigênio dissolvido $\left(\mathrm{mg} \mathrm{L}^{-1}\right)$ & $6,47 \pm 0,34 \mathrm{a}$ & $6,36 \pm 0,38 \mathrm{a}$ \\
$\mathrm{pH}$ & $8,32 \pm 0,13 \mathrm{a}$ & $8,25 \pm 0,17 \mathrm{a}$ \\
Salinidade (\%) & $35 \mathrm{a}$ & $35 \mathrm{a}$ \\
$\mathrm{NO}_{2}\left(\mathrm{mg} \mathrm{L}^{-1}\right)$ & $0,01 \pm 0,004 \mathrm{a}$ & $0,02 \pm 0,01 \mathrm{~b}$ \\
$\mathrm{NH}_{3}\left(\mathrm{mg} \mathrm{L}^{-1}\right)$ & $0,75 \pm 0,40 \mathrm{a}$ & $0,56 \pm 0,28 \mathrm{a}$ \\
\hline Desempenho & & \\
$\quad$ Peso (mg) & $1,90 \pm 0,54 \mathrm{a}$ & $2,08 \pm 0,52 \mathrm{a}$ \\
Comprimento (mm) & $8,78 \pm 0,75 \mathrm{a}$ & $8,93 \pm 0,66 \mathrm{a}$ \\
Sobrevivência (\%) & $74,3 \pm 5,46 \mathrm{a}$ & $83,76 \pm 9,79 \mathrm{a}$ \\
\hline
\end{tabular}

(1)Médias seguidas de letras iguais, na mesma linha, não diferem pelo teste $\mathrm{t}$ de Student, a 5\% de probabilidade.
A sobrevivência dos camarões no tratamento com probióticos não diferiu significativamente do tratamento controle (Tabela 1). Os resultados obtidos no presente trabalho estão de acordo com os de Decamp et al. (2008), que compararam a adição de probiótico (Bacillus spp.) com um tratamento profilático (antibiótico) e um tratamento sem ambos os produtos no cultivo de $P$. monodon entre os estágios de Náuplio e $\mathrm{PL}_{10}$. Esses autores relataram maior sobrevivência nos tratamentos com probiótico e antibiótico, em comparação ao tratamento controle (sem adição de ambos); no entanto, não foram observadas diferenças significativas.

Não houve diferenças significativas entre os tratamentos na concentração de bactérias do gênero Vibrio na água, ao longo do período experimental (Figura 1). A concentração de Vibrio spp. na água de cultivo não influenciou a sobrevivência dos camarões nos diferentes tratamentos. Esse fato pode estar relacionado à possível presença de víbrios não patogênicos na água de cultivo. De acordo com Gomez-Gil et al. (2000), existem espécies de víbrios caracterizadas como benéficas ou como patogênicas aos peneídeos. Esses autores caracterizaram o $V$. alginolyticus como benéfico ao camarão L. vannamei, enquanto Lee et al. (1996) classificaram a mesma espécie como patogênica a $P$. monodon. Além disso, os víbrios são oportunistas e causam doenças e mortalidades em animais apenas quando estes se encontram fisiologicamente estressados (Alderman \& Hastings, 1998). Provavelmente, os resultados obtidos quanto ao crescimento e à sobrevivência devem-se à manutenção de condições ambientais

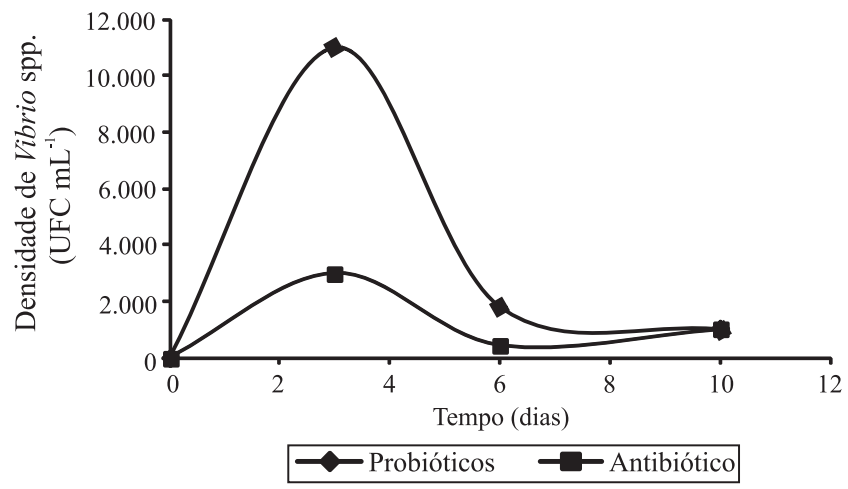

Figura 1. Concentração de Vibrio spp. na água de cultivo nos tratamentos com probióticos ou controle, com antibiótico, no cultivo de pós larvas do camarão-rosa Farfantepenaeus brasiliensis. 
e alimentares adequadas durante o experimento, as quais não proporcionaram estresse fisiológico aos animais. Segundo Rengpipat et al. (2000), a redução do estresse pode ser usada para aumentar a resistência dos camarões a doenças, e o estresse causado pela má qualidade de água, por exemplo, pode deixar os camarões suscetíveis a patógenos. No tratamento com probióticos, a concentração de Vibrio spp. diminuiu após o terceiro dia de cultivo, o que provavelmente está relacionado à ação dos Bacillus spp. Moriarty (1998) e Verschuere et al. (2000) reportaram que Bacillus spp. são capazes de competir com outras bactérias, como Vibrio, por nutrientes e espaço, e também podem excluir outras bactérias pela produção de antibióticos, o que aumenta sua proporção na flora intestinal dos camarões.

Para os aspectos qualitativos das pós-larvas, não foram observadas diferenças significativas entre os tratamentos, segundo os critérios avaliados,

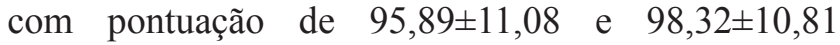
para os tratamentos com probiótico e controle, respectivamente.

A avaliação da saúde de larvas e pós-larvas de crustáceos estocados em viveiros tem se tornado um fator importante, particularmente para a produção de camarões, uma vez que a sua qualidade pode influenciar a produção final (Tayamen \& Brown, 1999). Diversos critérios são utilizados na determinação da qualidade das pós-larvas, e incluem: estágio de desenvolvimento das pós-larvas - quanto maior o grau de desenvolvimento maior a chance de sobrevivência (Parado-Estepa, 1988) -, sobrevivência, coloração, desenvolvimento do músculo, e atividade das larvas e pós-larvas (Bauman \& Jamandre, 1990). Outros critérios, como a repleção do intestino, a presença de detritos nos apêndices, a deformidade do corpo e as condições do músculo, também têm sido considerados.

A utilização de técnicas para a determinação da qualidade das pós-larvas de camarões permite avaliar a viabilidade das condições de cultivo utilizadas em sistema de larvicultura, assim como correlacionar a qualidade das pós-larvas com o posterior desempenho de determinadas espécies durante a fase de crescimento. Além disso, como ferramenta de pesquisa, essas técnicas permitem avaliação qualitativa de um determinado estoque, o que pode ser muito útil para trabalhos experimentais (Bauman \& Jamandre, 1990).
No presente trabalho, a utilização de probiótico ou de antibiótico não interferiu na qualidade das pós-larvas de F. brasiliensis. O método de avaliação da qualidade das pós-larvas tem sido utilizado com sucesso em larviculturas comerciais na Tailândia, na Malásia e nas Filipinas para identificar problemas de manejo (Tayamen \& Brown, 1999).

\section{Conclusões}

1. A utilização de probiótico ou antibiótico no cultivo de pós-larvas $\left(\mathrm{PL}_{10}\right)$ de Farfantepenaeus brasiliensis não influencia os parâmetros físicos e químicos da água, nem o crescimento e a sobrevivência dos animais.

2. A concentração de Vibrio spp. na água de cultivo se mantém semelhante quando se utiliza probióticos ou antibiótico no cultivo.

3. Pode-se eliminar o uso de antibiótico no cultivo de pós-larvas de $F$. brasiliensis.

4. A utilização de probióticos ou antibiótico durante o cultivo não influencia a qualidade das pós-larvas de F. brasiliensis.

\section{Agradecimentos}

Ao Conselho Nacional de Desenvolvimento Científico e Tecnológico e à Coordenação de Aperfeiçoamento de Pessoal de Nível Superior, pelo apoio financeiro; e à Gabriele de Lara e à Carla Bueno, pela ajuda na execução do experimento.

\section{Referências}

ALDERMAN, D.J.; HASTINGS, T.S. Antibiotic use in aquaculture: development of antibiotic resistance-potential for consumer health risks. International Journal of Food Science and Technology, v.33, p.139-155, 1998.

BANERJEE, S.; KHATOON, H.; SHARIFF, M.; YUSOFF, F.M. Enhancement of Penaeus monodon shrimp postlarvae growth and survival without water exchange using marine Bacillus pumilus and periphytic microalgae. Fisheries Science, v.76, p.481-487, 2010.

BAUMAN, R.H.; JAMANDRE, D.R. A practical method for determining quality of Penaeus monodon (Fabricius) fry for stocking in grow-out ponds. In: AQUATECH CONFERENCE ON TECHNICAL AND ECONOMIC ASPECTS OF SHRIMP FARMING, 1990, Kuala Lumpur. Proceedings. Kuala Lumpur: Infofish, 1990. p.124-137.

BENDSCHNEIDER, K.; ROBINSON, R.J. A new spectrophotometric method for the determination of nitrite in sea water. Journal of Marine Research, v.11, p.87-96, 1952. 
BOYD, C.E. Water quality in ponds for aquaculture. Alabama: Auburn University, 1990. 482p.

BRITO, R.; CHIMAL, M.E.; ROSAS, C. Effect of salinity in survival, growth, and osmotic capacity of early juveniles of Farfantepenaeus brasiliensis (Decapoda: Penaeidae). Journal of Experimental Marine Biology and Ecology, v.244, p.253-263, 2000 .

CHEMICAL methods for use in marine environmental monitoring. Paris: Intergovernmental Oceanographic Commission, 1983. 53p.

DECAMP, O.; MORIARTY, D.J.W.; LAVENS, P. Probiotics for shrimp larviculture: review of field data from Asia and Latin America. Aquaculture Research, v.39, p.334-338, 2008.

DEFOIRDT, T.; BOON, N.; SORGELOOS, P.; VERSTRAETE, W.; BOSSIER, P. Alternatives to antibiotics to control bacterial infections: luminescent vibriosis in aquaculture as an example. Trends in Biotechnology, v.25, p.472-479, 2007.

GAXIOLA, G.; GALlARDO, P.; SIMÔES, N.; CUZON, G. A red shrimp, Farfantepenaeus brasiliensis (Latreille, 1817), larvae feeding regime based on live food. Journal of the World Aquaculture Society, v.41, p.402-410, 2010.

GOMEZ-GIL, B.; ROQUE, A.; TURNBULL, J.F. The use and selection of probiotic bacteria for use in the culture of larval aquatic organisms. Aquaculture, v.191, p.259-270, 2000.

GRAM, L.; MELCHIORSEN, J.; SAPNGGAARD, B.; HUBER, I.; NIELSEN, T.F. Inhibition of Vibrio anguillarum by Pseudomonas fluroscens AH2, a possible probiotic treatment for fish. Applied and Environmental Microbiology, v.65, p.969-973, 1999.

HONG, H.A.; DUC, L.H.; CUTTING, S.M. The use of bacterial spore formers as probiotics. FEMS Microbiology Review, v.29, p.813-835, 2005.

KARUNASAGAR, I.; PAI, R.; MALATHI, G.R.; KARUNASAGAR, I. Mass mortality of Penaeus monodon larvae due to antibiotic-resistant Vibrio harveyi infection. Aquaculture, v.128, p.203-209, 1994.

LAKSHMANAN, R.; SOUNDARAPANDIAN, P. Effect of commercial probiotics on large scale culture of black tiger shrimp Penaeus monodon (Fabricius). Research Journal of Microbiology, v.3, p.198-203, 2008.

LEE, K.-K.; YU, S.-R.; CHEN, F.-R.; YANG, T.-I; LIU, P.-C. Virulence of Vibrio alginolyticus isolated from diseased tiger prawn, Penaeus monodon. Current Microbiology, v.32, p.229-231, 1996.

LOPES, D.L. de A.; WASIELESKY JUNIOR, W.; BALLESTER, E.C.; PEIXOTO, S.R.M. Análise comparativa da criação dos camarões-rosa Farfantepenaeus brasiliensis e Farfantepenaeus paulensis criados em gaiolas em ambiente estuarino. Ciência Rural, v.39, p.1540-1546, 2009.

MORIARTY, D.J.W. Control of luminous Vibrio species in penaeid aquaculture ponds. Aquaculture, v.164, p.351-358, 1998.

PANIGRAHI, A.; KIRON, V.; KOBAYASHI, T.; PUANGKAEW, J.; SATOH, S.; SUGITA, H. Immune responses in rainbow trout Oncorhynchus mykiss induced by a potential probiotic bacteria Lactobacillus rhamnosus JCM 1136. Veterinary Immunology and Immunopathology, v.102, p.379-388, 2004.

PARADO-ESTEPA, F.D. Selection, transport and acclimation of prawn fry. In: CHIU, Y.N.; SANTOS, L.M.; JULIANO, R.O. (Ed.). Technical consideration for the management and operation of intensive prawn farms. Ilo-ilo City: Aquaculture Society, 1988. p.81-85.

RAVI, A.V.; MUSTHAFA, K.S.; JEGATHAMMBAL, G.; KATHIRESAN, K.; PANDIAN, S.K. Screening and evaluation of probiotics as a biocontrol agent against pathogenic Vibrios in marine aquaculture. Letters in Applied Microbiology, v.45, p.219-223, 2007.

RENGPIPAT, S.; RUKPRATANPORN, S.; PIYATIRATITIVORAKUL, S.; MENASAVETA, P. Immunity enhancement in black tiger shrimp (Penaeus monodon) by a probiont bacterium (Bacillus S11). Aquaculture, v.191, p.271-288, 2000.

STATSOFT. Statistica: data analysis software system. Version 7. Tulsa: StatSoft, 2004. Disponível em: <http://www.statsoft.com>. Acesso em: 30 maio 2012.

TAYAMEN, M.; BROWN, J.H. A condition index for evaluating larval quality of Macrobrachium rosenbergii (de Man 1879). Aquaculture Research, v.30, p.917-922, 1999.

VERSCHUERE, L.; ROMBAUT, G.; SORGELOOS, P.; VERSTRAETE, W. Probiotic bacteria as biological control agents in aquaculture. Microbiology and Molecular Biology Reviews, v.64, p.655-671, 2000.

WANG, Y.-B.; XU, Z.-R.; XIA, M.-S. The effectiveness of commercial probiotics in northern white shrimp Penaeus vannamei ponds. Fisheries Science, v.71, p.1036-1041, 2005.

ZIAEI-NEJAD, S.; REZAEI, M.H.; TAKAMI, G.A.; LOVETT, D.L.; MIRVAGHEFI,A.; SHAKOURI, M. The effect of Bacillus spp. bacteria used as probiotics on digestive enzyme activity, survival and growth in the Indian white shrimp Fenneropenaeus indicus. Aquaculture, v.252, p.516-524, 2006.

ZIEMANN, D.A.; WALSH, W.A.; SAPHORE, E.G.; FULTON-BENNET, K. A survey of water quality characteristics of effluent from Hawaiian aquaculture facilities. Journal of the World Aquaculture Society, v.23, p.180-191, 1992.

Recebido em 29 de dezembro de 2010 e aprovado em 3 de maio de 2012 